\title{
La fábula histórica en Alfonso Reyes
}

\author{
Clara María Parra Triana \\ Pontificia Universidad Católica de Valparaíso, Chile
}

Resumen:

Propongo en este ensayo una reflexión sobre los modos en los que opera la Historia en la escritura alfonsina, resumidos en la noción de "fábula histórica", la cual alude a los procedimientos de lectura que de la tradición realiza Alfonso Reyes a manera de intermediario subjetivizado; los caminos de escritura que elige para representar fragmentos del pasado histórico, mítico, literario, y que constituyen el particular posicionamiento de Reyes en torno al realismo, y la conjunción cooperativa que realizó el escritor mexicano de la lectura y la escritura para suscribir el presente a una experiencia de constante recreación crítica de la historia.

Palabras clave:

Lectura, escritura, fábula, historia/Historia, Alfonso Reyes.

Abstract:

In this essay it is proposed a reflection about the ways History is shown in Alfonso Reyes' writing, which are summed up in the notion of "historical fable" that refers to the tradition reading procedures carried out by Alfonso Reyes as a subjectivized intermediary; the writing ways 
to represent parts of historic, mythical or literary past which make his particular view of realism, and the cooperative conjuntion of reading and writing that this mexican writer made in order to endorse the present to a permanent experience of critical recreation of History.

Keywords:

Reading, Writing, Fable, Story/History, Alfonso Reyes.

Tas renovadas y polémicas preguntas sobre el realismo en las esLcrituras contemporáneas están llevando a los lectores actuales a una confrontación — cada vez más airada y exigente — con los modos de representación que las novísimas perspectivas arrojan, sobre los asuntos que, llevados al plano artístico, pretenden entregar visiones sugestivamente críticas. De modo que, las así llamadas "narrativas del yo", las escrituras cada vez más intimistas, la búsqueda del verosímil subjetivizado, el empecinado recurso al archivo y las modalidades discursivas que habían logrado escapar al encasillamiento de lo ficticio — tales como las cartas, diarios y memorias-, son apenas algunos ejemplos de esta irregular pero sobre todo común atmósfera de crisis del realismo que se condice - quizás-, con la pretensión de relatar lo no contado, de reconocer lo no clasificado y de exhibir lo oculto, corriendo también el riesgo de generar suspicacias por las reivindicaciones, rescates y protestas que desde diversas lecturas politizadas podría adjudicársele a estos procedimientos escriturales.

Este tipo de confrontación con el arte y sus modos de representación no es meramente un asunto contemporáneo. La discusión es vieja, como antiguos son sus referentes; si se quiere revisar un ejemplo paradigmático de esta disputa se podría ir tan lejos como sea posible solamente registrando lo que ha sido de los modos de escritura de la historia. Pero esta es ya tarea ardua, y como la escritura es siempre aspiración pero también límite, se tomará acá 
el caso particular de la escritura de la historia que Alfonso Reyes exploró en diversas modalidades y que, para la lectura que aquí se propone, persigue la forma no convencional de la "fábula histórica", la cual echa mano mayoritariamente de un procedimiento de lectura que se registra como ocasión para la escritura actualizada no del pasado sino de las construcciones-representaciones que el hombre va realizando de sí mismo, y que constituyen un primario modo de crítica no convencional ni directa sino siempre revestida de divagaciones "imaginarias" que ponen en cuestión el paso del tiempo y las variaciones que se pueden realizar en torno a éste ${ }^{1}$.

La fábula histórica, así entendida, busca ampliar el espectro de lectura que propuestas como la de Eugenia Houvenaghel (2003) realizaron en torno a la argumentación del ensayo histórico de Alfonso Reyes. La lectura que Houvenaghel sostiene - desde las herramientas de la neoretórica (Perelman) y tomando textos emblemáticos de la escritura alfonsina-, apunta a que, en la argumentación histórica de Reyes, se pueden reconocer los mecanismos en los que se hace legible una persuasión política que concilia las posiciones antihispanistas y prohispanistas, y que fundamentara una construcción identitaria americana. Uno de los aspectos que

${ }^{1}$ La historia en la escritura alfonsina ha sido uno de los temas más atrayentes para los lectores de Reyes. Ha llamado sobre todo la atención su modo de ensayar históricamente en torno a América. Sus ensayos "Visión de Anáhuac", "El presagio de América" o "Notas para una inteligencia americana", además de ser emblemáticos de su escritura, le han facilitado a sus lectores las más variadas interpretaciones críticas en torno a la conciencia histórica americana. En mi caso, arriesgué una lectura sobre su visión de la historia literaria en sintonía y complemento con las visiones de Pedro Henríquez Ureńa y José Carlos Mariátegui además de su americanismo crítico derivado de la visión utopista del descubrimiento de América (La pugna secreta, 2013). Posteriormente, ensayé una lectura de la alegoría histórica en Alfonso Reyes y el ensayista chileno Martín Cerda, en Retorno a la palería dispersa, (en prensa), basada en un acercamiento a la escritura fragmentaria y a la visión de catástrofe y ruina presente en los textos de Ancorajes. 
puede ser debatible en torno a lecturas como la de la académica belga es el hecho de sucumbir a la clasificación prohispanista de Reyes, muy a pesar de la hipótesis inicial: el ensayo argumentativo alfonsino como forma de conciliación de las polaridades. El otro aspecto, sin duda controvertible, es el señalamiento de Houvenaghel sobre la tentativa de fracaso persuasivo de los ensayos de Reyes al recurrir a estrategias retóricas más complejas como la narración y la fantasía. La estudiosa belga le reconoce "belleza estilística" y "eficacia argumentativa" a estos procedimientos, pero no discute sobre el valor crítico que Reyes —en profunda clave iróni$\mathrm{ca}$ - monta sobre el valor de la elaboración ficticia y su derecho a infiltrarla a partir de las herramientas que la lectura le otorga para contribuir a los diferentes modos de representación de la historia ya sea americana, mexicana o de recurso al pasado al que se tiene derecho por la recepción directa más que por la recepción pasiva.

De modo que el procedimiento a seguir para conformar un acercamiento a la fábula histórica en Alfonso Reyes será el de constatar, en primera instancia, las visiones de la representación histórica que el escritor mexicano dejó apuntadas en breves pero significativos textos de Marginalia (1946-1951), Las burlas veras (1954-1955) y Los trabajos y los días (1934-1944) para analizar su correspondencia con la lectura de los historiadores clásicos que Reyes consignó en La crítica en la edad ateniense (1941) y Junta de sombras (1949); posteriormente, se abrirá la discusión sobre la fábula histórica como forma de representación crítica de la historia, tomando como ejemplo "Visión de Anáhuac" (1915) y Retratos reales e imaginarios (1920), mediante la consideración de algunas reflexiones modernas sobre la escritura histórica y su contribución al análisis crítico del discurso. 


\section{Apuntes sobre la idea de escritura de la historia en Alfonso Reyes}

Se cuida Alfonso Reyes de parecer dogmático en el asunto o disciplina al que sólo visita con cierta regularidad y en el que no tiene el más mínimo interés en quedarse, recordándonos con acento burlesco que "el que pretende decir siempre la última palabra, cuando la conversación no tiene fin, corre el riesgo de quedarse callado" (Reyes, 1997a: 12); lo que nos indica que encontrar un proyecto o programa afirmativo de cierto sistema de valores defendido desde los textos históricos de Reyes resulta ser en efecto más problemático que tratar de encontrar las diversas salidas interpretativas en las que el mexicano basó sus lecturas de la historia.

En "Mi idea de la historia" —ensayo escrito para el primer congreso de historiadores de México y los Estados Unidos en 1949nuestro pensador reitera el valor estético de la escritura de la Historia; y en ese valor estético, que traspasa los límites del buen escribir, se sustenta la "humanidad" del discurso histórico. El historiador es un "mago" que hace hablar la materia inerte: al museo, a las piedras, a los documentos. Donde un ojo común ve solo ruinas, el ojo del intérprete observa las posibilidades de habla. El discurso de la historia sería como un dialecto que representa una sincronía posible en el mapa de las lenguas del mundo, pues la posibilidad de edificar nuevamente a Roma o a la antigua Atenas es un derecho al que toda contemporaneidad apela: "siempre podría escribirse otra vez la historia de Egipto o la de Roma” (Reyes, 1989: 208).

No obstante, el derecho a la representación histórica se encuentra delimitado por un "triángulo de fuerzas" que constituye el "estímulo de la imaginación histórica" a la que Reyes recurre y tiende: "el dato comprobado", "la interpretación comprensiva" y "la buena forma artística”: 
la interpretación es esencial en la obra histórica y de que no puede sustituirla el museo de ejemplares históricos. Historia como colección de hechos sucedidos siempre la habrá, aunque nadie la exprese; pero si no ha pasado por el tamiz de la mente, carece de realidad humana. Historia como entendimiento de tales hechos, sus mutuas relaciones de antecedencia, concomitancia y consecuencia, y de su determinación o su efecto en el sentir de las sociedades humanas, no es ya posible sin la intervención y aportación de una mente, de un sujeto de discernimiento. Historia como la manifestación literaria, hablada o escrita con palabras, no puede haberla sin atención especial para la forma artística, la equilibrada composición en el conjunto y la cuidadosa dicción en el "fraseo" (Reyes, 1989: 208).

Esta triada explicada arriba pone en el centro de la discusión y como punto de encuentro la imaginación expresiva del historiador, a quien ni el finalismo ni el pragmatismo le deben arrebatar de las manos las elecciones y los modos de comprender los hechos. Este sencillo triángulo resiste críticamente a los lugares comunes de los métodos históricos o de los pseudohistoricismos empecinados en recalcar la verdad o en reflejar la realidad de un lado de los extremos, o el otro, el del exagerado y siempre necio relativismo histórico que niega valor a la narración, a su organización y a sus juicios de valor (ver Reyes, 1989: 452). Reyes incluso suma un tercer factor problemático que se encuentra en medio de los dos anteriores: el "ifismo" o enfermedad pseudohistórica que mediante hipótesis de entretenimiento se dedica a elucubrar sobre lo que hubiese sido del hombre si no hubiese actuado como actuó en el pasado. Este último — nos indica Reyes - es un procedimiento ameno estéticamente pero de poca relevancia histórica, porque en este caso la imaginación nada tiene que ver con el fárrago ni la palabrería. El ifismo (se justifica el anglicismo) no es, por supuesto, la salida ética ni estética de la escritura histórica de Reyes, pues no 
se dedica a generar divagaciones que alteren la suma del presente; antes bien, a partir del comienzo elegido y un final seleccionado procede a una interpretación comprensiva del pasado para que siga siendo contemporáneo.

\section{La lectura de los clásicos}

En la triada de historiadores clásicos — Heródoto, Tucídides y Jenofonte- ya presagia Reyes una de las visiones sobre la escritura de la Historia que será el fundamento para su "fábula histórica". En sus apuntes consignados en Junta de sombras y en La crítica en la edad ateniense resalta, más que la finalidad de las historias o la fidelidad de sus asuntos, los procedimientos de escritura en cada uno de ellos. A Heródoto, por ejemplo, procederá a quitarle el sobrenombre de "padre de la historia" para desmitificar su figura y entrar a debatir su modo de alegorizar, más que relatar verídicamente lo que en él sólo es compilación.

Consigna el pensador mexicano que lo que hay de historiadores en estos tres clásicos, lo tienen también de escritores, pues a la prosa histórica clásica Reyes le asigna el valor de una escritura que se quiere aparte de lo literario, pero que apenas alcanza a dibujar sus contornos. Pero este proceso de delimitación, o si se quiere de "emancipación" de la prosa histórica de los dominios de lo literario, para Reyes no significa una ganancia o tan siquiera una ventaja para la escritura de la historia; el hecho de hallarse a medio camino, justamente entre la interpretación de las fuentes, el crédito a su autoridad y la composición particular de una narrativa específica, le entrega a la prosa histórica la soberanía suficiente para erigirse como modalidad discursiva de autoconstrucción de la consciencia del hombre: 
La moderna pedantería científica [...] censura en Tucídides la ocultación de las fuentes. Pero tal ocultación no pasa de ser una manera artística, un efecto de la agilidad de estilo, y no ha quitado la menor autoridad a su obra, porque ella misma tiene el valor de fuente reconocida, y es notorio que Tucídides comprobaba antes de afirmar. También se le echa en cara el sustituir las pruebas documentadas con oraciones y discursos ficticios. Pero este procedimiento simbólico, fundado en su concepción dramática, en su esfuerzo sintético, y en aquella su filosofía que ve en las ideas la causa de los hechos, nunca falsea la interpretación, antes permite la más clara y rápida pintura de opiniones motivos y caracteres. Mero artificio de la expresión, no hace el menor daño una vez que se le reconoce su valor metafórico. A través de este bello artificio, Tucídides logra, como se ha dicho, dotar de alma el cuerpo de la historia (Reyes, 1997c: 77).

Con la anterior cita se puede apreciar la tradición historiográfica a la que adhiere Reyes. El verdadero peso historiográfico se encuentra en la escritura y no en el dato, pues un lector que no caiga en la trampa de cientificismo intentará recuperar la interpretación, para armar la suya propia y así participar de la construcción de la fábula histórica a la que se accede por la vía de la experiencia lectora del pasado y el cuestionamiento ensayístico del presente. Con esto, también podemos descartar que la visión de la historia en la escritura alfonsina sea aristotélica, si por esta entendemos la devaluación de la Historia frente a la poesía, porque "la Historia solo narraría "lo que ha pasado» mientras que la poesía narra "lo que podría pasar»" (Koselleck, 2010: 48); Reyes vuelve a Aristóteles, pero no para demeritar la práctica histórica si no para patentar desde una visión moderna de la escritura histórica lo que esta tiene que contribuir a las posibilidades de comprensión más que a las posibilidades de ser de la Historia. 


\section{Historia escrita e historia leída: la fabulación histórica}

Entre la Historia como disciplina y la historia como escritura Reyes opta por la segunda, sin demeritar o excluir a la primera, antes bien procurando explorar sus límites y generar acercamientos con los potenciales valores humanos inscritos en la prosa histórica. ${ }^{2}$ Para Reyes el discurso histórico pervive porque se consolida como un modo de experimentar y sociabilizar más que un huero ejercicio de memoria. Teniendo presente que en la prosa histórica alfonsina se halla la visión de que la historia no se elabora mediante el "habla" del dato o del hecho antes bien por la interpretación que se lleva a cabo en las experiencias de lectura y de escritura, la fabulación se filtra e interviene el dato histórico reorganizándolo y entregándole la carga irónica del discurso crítico.

Enuncia nuestro ensayista en las últimas líneas de su "Visión de Anáhuac": "convéngase en que la emoción histórica es parte de la vida actual" (Reyes, 1986: 34), para recordarnos que en todas las imágenes expuestas en su fragmentada contemplación se vislumbra la experiencia domeńada por el paso del tiempo y por el cotejo y susurro de las versiones que intentan aplastarse las unas a las otras. En "Visión de Anáhuac", el sujeto de la enunciación recorre las páginas de la biblioteca viajera y de la mano de Humboldt, Fray Luis de Navarrete, Stevenson, Ramusio, Gómara, Díaz del Castillo, Ruíz de Alarcón — como Dante guiado por Virgilioobserva la desecación del valle que en casi cinco siglos pasa de la literal lucha del hombre ante las fuerzas de la naturaleza hacia la metafórica vocación del hombre de destruir lo que de vida hay en ella, "parece correr la consigna de secar la tierra" (Reyes, 1986: 15).

${ }^{2}$ Luís Rublúo, en "Pensamiento histórico de Alfonso Reyes", recorre las visiones de la historia en la prosa alfonsina para afirmar que la apuesta subjetiva de la historiografía a la que tiende Reyes rechaza al mismo tiempo una Filosofía general de la Historia. 
Recordemos que el ensayismo de Reyes en "Visión de Anáhuac" no se dedica sólo a un regreso al pasado colonial o al precolombino - ese es sólo el asunto que permite al ensayista cuestionar al presente y, de paso, cuestionarse a sí mismo como lector.

Las concepciones modernas de la escritura histórica ya dan por descartado que los datos y los hechos son los que hablan en el discurso histórico. La narrativización de éste posiciona a la figura del autor no en tanto autoridad sino en tanto intérprete posible, organizador de significaciones (R. Barthes, H. White), por lo que lo que nos encontramos en los discursos que recurren a la historia es la organización la lectura posible de lo inteligible más que de la realidad o de la verdad. Al ser apartados estos dos grandes dogmas del cientificismo — que Reyes rechazó de plano- la posibilidad de crear interpretando se hizo posible sin los miramientos disciplinares.

Como se puede ver, por su propia estructura y sin tener necesidad de invocar la sustancia del contenido, el discurso histórico es esencialmente elaboración ideológica, o, para ser más precisos, imaginario, si entendemos por imaginario el lenguaje gracias al cual el enunciante de un discurso (entidad puramente lingüística) «rellena» el sujeto de la enunciación (entidad psicológica o ideológica). Desde esta perspectiva resulta comprensible que la noción de "hecho" histórico haya suscitado a menudo una cierta desconfianza [...] A partir del momento en que interviene el lenguaje (¿y cuándo no interviene?), el hecho solo puede definirse de manera tautológica: lo anotado procede de lo observable — desde Heródoto, para el que la palabra ya ha perdido su acepción mítica - no es más que lo que es digno de memoria, es decir, digno de ser anotado (Barthes, 1987: 205).

Lo apuntado por Barthes, White y De Certeau nos posiciona en un espacio teórico en el que la "fábula histórica" ganaría un lugar en lo referente al "giro lingüístico en el discurso histórico", sin 
pretender que los problemas teórico-literarios esbozados por ellos y utilizados acá como recurso argumentativo reemplacen a los propiamente históricos. Por lo tanto, este ejercicio no se trata de un reemplazo de los problemas históricos por los literarios o de buscar una cierta correspondencia de intereses. Este ejercicio de lectura, y la idea de fábula histórica como su concreción, apuntan más bien a la comprensión de un recurso y de un posicionamiento contemporáneo ante la escritura crítica del pasado.

"Visión de Anáhuac" se consolida como una fábula histórica — quizá sea la más famosa, la más emblemática de Reyes— justamente por recurrir a la imagen poética antes que al señalamiento y denuncia directos que le arrebatan de experiencia presente su voluntad de representación histórica. Esta fábula se termina de escribir en 1915, pero sabemos que pretende exaltar — levantar a saltos disimulados - lo que queda de la desecación porfiriana: "No renunciaremos —oh Keats - a ningún objeto de belleza, engendrador de eternos goces" (Reyes, 1986: 34).

El peso del intertexto en "Visión de Anáhuac" es uno de los rasgos más peculiares de esta fabulación. Desde las palabras de Humboldt — tan reiteradamente citadas por lo que tienen de fascinantes - hasta la larga referencia a las meditaciones floridas de Netzahualcóyotl, la fábula es un diálogo ininterrumpido con las fuentes a las que les hace hablar el sujeto de la enunciación ensayístico-poética, como si se tratara de un coloquio entre tiempos, voces e imágenes. En la fábula histórica alfonsina es posible — como en las fábulas clásicas el lobo y el pastor conversan- que los dictadores del presente emulen los imperios del pasado y se conjuguen las sensibilidades actuales con los rasgos de la tierra colonizada, sorprendente y exagerada.

La concepción tradicional de "fábula" nos remite al relato breve con intenciones didácticas, que además se hallaba revestido de fantasía, para así potenciar, generalizar y despersonalizar su carga 
crítica hacia las costumbres del hombre (Beristáin, 1995). La fábula fue una forma autónoma preferida por la literatura ejemplarizante que pronto se incorporó como argumento a otras formas que perseguían diversos fines no necesariamente moralizantes; de modo que es posible para nosotros encontrar manifestaciones de fabulación en formas modernas que apelan a su elaborada ironía.

Parece decirnos el hablante del ensayismo alfonsino: lo que hago acá es leer sobre la colonización del nuevo mundo y escribir sobre cómo éste fuera representado con el asombro y la predisposición a la fantasía propia de las mentes ya contaminadas de las fabulaciones librescas. Lo que habla — fabla — en las crónicas del siglo XVI son las lecturas de los hombres y su disposición a interpretar así el nuevo mapa del mundo.

La práctica de la historia es un ejercicio modernizante en la prosa alfonsina; y esta práctica encuentra su "límite" en el marco capturado entre la lectura y la escritura. "El límite — nos recuerda De Certeau - se convierte en instrumento y objeto de investigación a la vez" (1997: 57); para Reyes no hay historia fuera de la lectura y lo que él hace es recapitular lo leído desde la experiencia del presente. Por ello, cobra sentido la advertencia que los modernos estudiosos del discurso histórico realizan acerca de la inutilidad y ociosidad de pretender discriminar la experiencia histórica de su representación. Así, la experiencia de lectura en Reyes se condice con la búsqueda de modos de representación a partir de las huellas que el mexicano personaliza como argumentos de la experiencia leída y que le autorizan en tanto intérprete, no en tanto voz ostentadora de la verdad.

Recordemos que Roland Barthes en su ensayo "El discurso de la historia" (1967) cuestiona la naturaleza "real" y "científica" del discurso histórico preguntando si se justifica la distinción entre los relatos "reales" y los "imaginarios": "¿difiere realmente, por algún rasgo específico, por alguna indudable pertinencia de la narración 
imaginada, tal como la podemos encontrar en la epopeya, la novela, el drama? Y ese rasgo —o esa pertinencia- existe, ¿en qué punto del sistema discursivo, en qué nivel de la enunciación hay que situarlo?” (1987: 163-164). El estudioso francés recupera una serie de marcas discursivas o shifters del sistema jakobsoniano para precisar que la ilusión de los discursos "de pretensión realista" se delata en la medida que enuncian sus fuentes haciendo coexistir el "tiempo de la enunciación" y el "tiempo de la materia enunciada".

En Reyes, estos "shifters" o rasgos de enunciación no son problemáticos — su pretensión no es realista— pues resultan ser recursos de apropiación y conjunción de los tiempos dialogantes a partir de la experiencia de lectura. La frase "según mi conocimiento" es reemplazada por "quieren hacernos creer" o "ha podido decir el poeta" cuyo sentido se orienta a ironizar la verosimilitud, a incorporar la duda y a marcar el punto de vista de la fuente leída y traspasada por su segunda mano.

Ejemplo paradigmático de estos procedimientos de escritura son sus "Retratos reales e imaginarios" (1920), asociados a la modalidad de ficciones enciclopédicas de connotada erudición equilibrada con vuelo imaginativo. Estos retratos, herederos de los Imaginary portraits (1887) de Walter Pater, parten del efecto metonímico de perseguir en un nombre particular los efectos de largo alcance histórico de sus acciones. Así, podemos leer que su Nebrija es una recreación del gramático que modernizó a Espańa; que su Madama Lucrecia pudo ser también algo más que una traidora; o que Lutero presagiaba ya la caída de la Edad Media europea y anunciaba la modernización de la lengua alemana.

Pero la fábula histórica de los retratos de Reyes se levanta con sutileza por sobre los eventos históricos. Los hombres con los que dialoga se hallan a medio camino entre la carne y el hueso, el papel y la tinta. Su Chateaubriand — nos recuerda Reyes— "hacía mucho tiempo que [...] viajaba en la imaginación, por América, 
cuando, en el año 1791, desembarcó en Baltimore" (1980: 420), y no por ello se le habría de tildar de plagiario. La fabulación histórica es una fuente asociativa de signos inteligibles y la obra de Chateaubriand sería uno de los modelos de "refundición y transcripción como un verdadero método de invención poética" (420). Si Chateaubriand no reparó en distinguir sus fuentes enciclopédicas de las literarias o incluso de su propia experiencia biográfica, como tampoco lo hizo Hecateo, el historiador alejandrino, quien aseguraba ser descendiente directo de los dioses, el procedimiento de la fábula histórica, desde esta perspectiva demuestra su larga data y su arraigo como recurso persuasivo ante las premuras de las certezas.

Y si hay personalidad resbaladiza a las certezas, pero representativa por los irónicos embates de la vida, las decisiones y los vicios remotos, esa es la de Fray Servando Teresa de Mier, el cura mexicano que le permite a Reyes usar el "acaso" como un "shifter" imaginativo para rellenar las escenas, de suyo burlescas, de los avatares coloniales proindependentistas en la ensombrecida Europa y la airada América. El padre Mier constituye en sí mismo — como personaje casi mítico - la encarnación del fabulador histórico por antonomasia. Sus sermones y memorias juntan indistintamente la tradición religiosa prehispánica con la versión guadalupana del catolicismo para emitir un grito independentista tan marcadamente irónico por ser carne de su propia carne, que como bien nos señala Reyes "sus memorias están escritas con apasionamiento, y más se parecen a una caricatura que a un retrato. Por eso mismo nos permiten percibir de una vez dos o tres vicios fundamentales de la sociedad en que vivió" (1980: 438). La fabulación histórica, en los "Retratos reales e imaginarios", pasa de ser recurso de narrativización histórica a ser sátira del pasado leído y del “irritante” presente. 


\section{Conclusiones}

Convengamos, por fin, en que la fábula histórica alfonsina supera los límites del recurso retórico y afirmativo de un sistema de valores programático, para posicionarse como una de sus visiones poéticas que la crítica moderna realiza a los grandes relatos históricos y a sus pretendidas voces de autoridad. No hay desdén en Reyes hacia la Historia; en él hay homenaje y hay propuesta. Desde esta perspectiva la historia no se puede leer reiterándola, reafirmándola o repitiéndola; su reescritura constituye una conjunción creativa de lectura y experiencia presente, con la constante aspiración a que no haya solo una única y acabada versión del relato, y a que la voz del historiador sea reemplazada por la del tramoyista.

El escenario colonial americano, pero también la Europa de los Borgias, los viajes de Chateaubriand, incluso la España áurea de Gracián, resultan ser retratos que se han colgado en nuestro imaginario para conocimiento, deleite y crítica de nuestro presente. Su renovada exploración, mediante fabulaciones históricas que nos recrean los procesos de escritura de sus protagonistas, su actitud vital, sus imprecisiones y hasta sus mentiras voluntarias, nos entregan experiencias de lectura vívidas y creativas que le recuerdan al lector contemporáneo que siempre se puede vivir en el beneficio de la duda; y que los relatos, a pesar de que puedan ser autobiográficos de grandes sabios como Nebrija o Cordera, o sacados del mismísimo archivo en donde reposan las más primigenias versiones no nos entregan la certeza ni el microrelato personal y en la gran épica de las naciones modernas. Pero certeza no tiene que ver con creación y por eso los "Retratos reales e imaginarios" de Reyes nos sugieren "imaginar teatralmente" los documentos para así poder leer como si viéramos a los personajes "por el agujero de la llave". 


\section{Bibliografía}

Barthes, Roland, 1987, "El discurso de la historia" [1967], El susurro del lenguaje. Más allá de la palabra y la escritura, C. Fernández Medrano (trad.), Barcelona, Paidós.

Beristáin, Helena, 1995, Diccionario de retórica y poética, México, Porrúa.

Chartier, Roger, 2005, El mundo como representación. Estudios sobre historia cultural, Claudia Ferrari (trad.), Barcelona, Gedisa.

De Certeau, Michel, 1994, La escritura de la historia, José López Moctezuma (trad.), México, Universidad Iberoamericana.

Houvenaghel, Eugenia, 2003, Alfonso Reyes y la Historia de América. La argumentación del ensayo histórico: un análisis retórico, México, FCE.

Koselleck, Reinhart, 2010, historial Historia Antonio Gómez Ramos (intro. y trad.), Madrid, Trotta.

Reyes, Alfonso, 1980, "Retratos reales e imaginarios", Obras completas, t. III, México, FCE.

, 1986, "Visión de Anáhuac", Obras completas, t. II, México, FCE.

, 1989, "Marginalia”, "Las burlas veras", Obras completas, t. XXII, México, FCE.

, 1996, "Los trabajos y los días", Obras completas, t. IX, México, FCE.

, 1997a, "Utopía de América", Obras completas, t. XI, México, FCE.

, 1997b, "La crítica en la edad ateniense", Obras completas, t. XIII, México, FCE.

, 1997c, "Junta de sombras", Obras completas, t. XVII, México, FCE. 
Rublúo, Luís, 1996, "Pensamiento histórico de Alfonso Reyes", Más páginas sobre Alfonso Reyes, James Willis Robb (pról. y comp.), v. III, México, El Colegio Nacional, pp. 982-994.

White, Hayden, 2010, Ficción histórica, historia ficcional y realidad histórica, Verónica Tozzi (sel., ed., e intro.), Buenos Aires, Prometeo libros.

(Recibido: 14 de enero de 2015, aceptado: 2 de febrero de 2015) 